University of South Florida

DIGITAL COMMONS

Digital Commons @ University of

@ UNIVERSITY OF SOUTH FLORIDA

South Florida

$1-1991$

\title{
On the Annual Cycle of Equatorial Upwelling in the Central Atlantic-Ocean
}

Thomas J. Weingartner

University of South Florida

Robert $\mathrm{H}$. Weisberg

University of South Florida, weisberg@marine.usf.edu

Follow this and additional works at: https://digitalcommons.usf.edu/msc_facpub

Part of the Marine Biology Commons

\section{Scholar Commons Citation}

Weingartner, Thomas J. and Weisberg, Robert H., "On the Annual Cycle of Equatorial Upwelling in the Central Atlantic-Ocean" (1991). Marine Science Faculty Publications. 143.

https://digitalcommons.usf.edu/msc_facpub/143

This Article is brought to you for free and open access by the College of Marine Science at Digital Commons @ University of South Florida. It has been accepted for inclusion in Marine Science Faculty Publications by an authorized administrator of Digital Commons @ University of South Florida. For more information, please contact digitalcommons@usf.edu. 


\title{
On the Annual Cycle of Equatorial Upwelling in the Central Atlantic Ocean
}

\author{
THOMAS J. WEINGARTNER* AND ROBERT H. WEISBERG \\ Department of Marine Science, University of South Florida, St. Petersburg, Florida
}

(Manuscript received 4 May 1989, in final form 11 June 1990)

\begin{abstract}
The annual cycle of the upper ocean's vertical velocity component $(w)$ on the equator at $28^{\circ} \mathrm{W}$ is examined by integrating the continuity equation using current meter data from the Seasonal Response of the Equatorial Atlantic Experiment. The annual cycle consists in part of an intense, but brief $(\sim 1$ month $)$, upwelling season beginning with the onset of strong easterly wind stress in boreal spring. This upwelling is followed by weaker downwelling during the summer despite the persistence of strong easterly wind stress. The record-length averaged $w$ profile shows that maximum upwelling $\left(0.6 \times 10^{-3} \mathrm{~cm} \mathrm{~s}^{-1}\right)$ is located slightly above the core of the Equatorial Undercurrent and downwelling is located below the base of the thermocline. The standard deviations are about tenfold the magnitude of the means. Independent evidence supporting these results are that 1) sea surface temperature (SST) is related to $w$ during the springtime changes in easterly wind stress with the observed and computed isotherm displacements in agreement, 2) temperature and $w$ are coherent and in quadrature within the thermocline over a broad range of frequencies exclusive of the instability wave band, 3 ) during the instability wave season, upwelling is associated with increasing SST and the vertical Reynolds' heat flux is maximum and divergent in the thermocline, and 4) after the instability waves abate, $w$ and easterly wind stress are coherent and out-of-phase. The observed evolution of $w$ differs from that implied by climatology, and these differences are attributed to the ocean's response to rapidly varying winds that are observed in-situ versus slowly varying winds characteristic of climatology.
\end{abstract}

\section{Introduction}

In his classic description of water property distributions in the near surface equatorial Atlantic Ocean, Defant (1936) conceived of a meridional circulation cell that included poleward flow at the surface and equatorward flow within the thermocline. Vertical communication between these two horizontal branches of the cell was achieved by the sinking of surface waters at higher latitudes and the ascending of thermocline waters on the equator. Applying isentropic analysis and Ekman wind-drift theory, Cromwell (1953) proposed that the meridional circulation cell was induced by the prevailing Southeast Trade Winds which maintained a surface convergence (downwelling) at about $3^{\circ} \mathrm{N}$ and a surface divergence (upwelling) on the equator. He reasoned that this convergence/divergence pattern was responsible for the strong SST front at about $3^{\circ} \mathrm{N}$, the low equatorial sea surface temperature (SST), and the enhanced biological productivity along the equator. Stommel (1960) extended Ekman's theory to the equator by including geostrophic pressure gradients and

\footnotetext{
* Present Address: Institute of Marine Science, University of Alaska, Fairbanks, Alaska.

Corresponding author address: Dr. Robert $H$. Weisberg, Department of Marine Science, University of South Florida, St. Petersburg, FL 33701.
}

in so doing provided an analytical demonstration of the meridional circulation cell. These models were corroborated by Knauss's (1966) measurements of equatorward flow within the thermocline and with his estimation of equatorial upwelling rates of order $10^{-3}$ $\mathrm{cm} \mathrm{s}^{-1}$, a speed that is about two orders of magnitude greater than that estimated for the oceanic gyres of midlatitudes.

Since equatorial oceans are characterized by shallow thermoclines and swift, vertically sheared currents, the existence of such large upwelling rates implies that vertical advection of heat and momentum are important for both the local and basin-wide thermodynamic and dynamic balances. Moreover, equatorial upwelling has global climatic significance. In the Atlantic it is related to the northward transport of heat. Observations (e.g., Roemmich 1983) and models (e.g., Sarmiento 1986; Philander and Pacanowski 1986) indicate that a net equatorial upwelling is required in the Atlantic Ocean to connect the equatorward, geostrophic transport of thermocline waters calculated at $8^{\circ} \mathrm{S}$ with the poleward, Ekman transport of surface waters calculated at $8^{\circ} \mathrm{N}$. The net northward heat flux increases across the equator as the upwelled water is heated by air-sea exchange.

Despite these implications, direct observations of equatorial upwelling have been hampered by the small speeds associated with the vertical velocity component $(w)$ field. Instead, vertical motion has been inferred by indirect methods. Historically, these inferences have 
been made from averaged heat, salt, or mass balances (Wyrtki 1981; Hansen and Paul 1984; Bryden and Brady 1985; Roemmich 1983; Wunsch 1984a), tracer distributions (Broecker et al. 1978; Quay 1983; Fine et al. 1983; Wunsch 1984b), or from short period isothermal displacements (e.g., Wyrtki and Eldin 1982). While such estimates are useful, they are incapable of addressing the seasonal variability of the $w$ field and the role of advective effects on the seasonally varying momentum and heat balances. Clearly, estimates of the time dependent $w$, which evolves as a consequence of local and nonlocal effects, are required. Toward this end Halpern and Freitag (1987, hereafter referred to as HF), Halpern et al. (1989), and Bubnov (1987) have used moored current meter observations from the Pacific Ocean to compute time series of $w$ by vertically integrating the continuity equation.

During the Seasonal Response of the Equatorial Atlantic Experiment (SEQUAL) approximately eight months of horizontal velocity data were collected from a triangular array of current meter moorings centered about the equator near $28^{\circ} \mathrm{W}$. These data are used herein to estimate time series of $w$ between the surface and the base of the thermocline at this location. The paper is organized as follows. Section 2 describes the field program, the data, and the computational procedure for calculating $w$. The seasonal evolution of $w$ is described in section 3. Independent corroborative analyses are given in section 4 . The results are then discussed with respect to previous observations and model results in section 5 , and the paper is summarized in section 6 .

\section{Data and methods}

The horizontal velocity component time series used to estimate $w$ are derived from a triangular array of four surface-buoyed current meter moorings located along the equator at $28^{\circ}$ and $24^{\circ} \mathrm{W}$ and along $28^{\circ} \mathrm{W}$ at $0.75^{\circ} \mathrm{N}$ and $0.75^{\circ} \mathrm{S}$. The current meters used in this study were set at depths of $10 \mathrm{~m}, 75 \mathrm{~m}$, and $150 \mathrm{~m}$ for the two off-equator moorings and at depths of $10 \mathrm{~m}$, $50 \mathrm{~m}, 75 \mathrm{~m}$, and $150 \mathrm{~m}$ for the two equatorial moorings. Table 1 shows the instrument types (EG\&G Sea Links Systems vector averaging and vector measuring current meters, VACMs, and VMCMs, respectively) and sampling durations. With the exception of one location, concurrent data are available at all of these depths for the period from 4 March 1983 through 2 November 1983 and at the $10 \mathrm{~m}$ depth through 20 March 1984. The record gap at $10 \mathrm{~m}$ depth at $0^{\circ}, 24^{\circ} \mathrm{W}$ from 17 May 1983 through 20 September 1983 resulted from a rotor failure.

The calculation of $w$ follows from the continuity equation,

$$
w_{z}=-\left(u_{x}+v_{y}\right)
$$

where $u$ and $v$ are the zonal and meridional velocity components, respectively, and the subscripts denote
TABLE 1. Record lengths of the moored current measurements used in this paper. For purposes of calculation of the vertical velocity component a common time interval of from 00004 March 1983 23002 November 1983 was used at 75 and $150 \mathrm{~m}$ depth. At $10 \mathrm{~m}$ depth a common time interval of from 0000 4 March 1983-2300 20 March 1984 was used.

\begin{tabular}{|c|c|c|c|c|}
\hline \multirow[b]{2}{*}{ Position } & \multirow{2}{*}{$\begin{array}{l}\text { Depth } \\
\text { (m) }\end{array}$} & \multirow{2}{*}{$\begin{array}{l}\text { Instrument } \\
\text { type }\end{array}$} & \multicolumn{2}{|c|}{ Duration } \\
\hline & & & Start & Stop \\
\hline $0^{\circ} 00^{\prime} \mathrm{N}$ & 10 & VACM & 190013 Feb 1983 & $190020 \operatorname{Mar} 1984$ \\
\hline \multirow[t]{3}{*}{$28^{\circ} 09^{\prime} \mathrm{W}$} & 50 & VACM & $190013 \mathrm{Feb} 1983$ & 190020 Mar 1984 \\
\hline & 75 & VACM & 190013 Feb 1983 & 190020 Mar 1984 \\
\hline & 150 & VACM & $190013 \mathrm{Feb} 1983$ & 20003 Nov 1983 \\
\hline $0^{\circ} 03^{\prime} \mathrm{N}$ & 10 & VMCM & 16003 Mar 1983 & 230017 May 1983 \\
\hline \multirow[t]{4}{*}{$23^{\circ} 59^{\prime} \mathrm{W}$} & 10 & VMCM & 000021 Sep 1983 & $100028 \mathrm{Mar} 1984$ \\
\hline & 50 & VACM & $16003 \mathrm{Mar} 1983$ & $100028 \mathrm{Mar} 1984$ \\
\hline & 75 & VACM & 16003 Mar 1983 & $100028 \mathrm{Mar} 1984$ \\
\hline & 150 & VACM & 16003 Mar 1983 & $100028 \operatorname{Mar} 1984$ \\
\hline $0^{\circ} 44 \mathrm{~N}$ & 10 & VACM & $230010 \mathrm{Feb} 1983$ & $070022 \operatorname{Mar} 1984$ \\
\hline \multirow[t]{2}{*}{$28^{\circ} 11^{\prime} \mathrm{W}$} & 75 & VACM & 230010 Feb 1983 & 070022 Mar 1984 \\
\hline & 150 & VACM & $230010 \mathrm{Feb} 1983$ & 070022 Mar 1984 \\
\hline $0^{\circ} 45^{\prime} \mathrm{S}$ & 10 & VACM & $220014 \mathrm{Feb} 1983$ & 160021 Mar 1984 \\
\hline \multirow[t]{2}{*}{$28^{\circ} 10^{\prime} \mathrm{W}$} & 75 & VACM & $220014 \mathrm{Feb} 1983$ & 20003 Nov 1983 \\
\hline & 150 & VACM & 220014 Feb 1983 & 160021 Mar 1984 \\
\hline
\end{tabular}

partial differentiation in the vertical ( $z$, positive upwards), zonal ( $x$, positive eastwards), and meridional ( $y$, positive northwards) directions. The zonal divergence, $u_{x}$, is calculated by forward differencing the $u$ component between the equatorial moorings at $24^{\circ}$ and $28^{\circ} \mathrm{W}$. The meridional divergence, $v_{y}$, is calculated by centered differencing the $v$ component between the moorings at $0.75^{\circ} \mathrm{N}$ and $0.75^{\circ} \mathrm{S}$ along $28^{\circ} \mathrm{W}$.

The zonal divergence at $10 \mathrm{~m}$ depth during the record gap of 17 May-20 September 1983 was estimated by linear mean square estimation utilizing the time series for $u_{x}$ at $50 \mathrm{~m}$ depth. A transfer function was calculated over the year long interval 21 September 1983-25 September 1984 between the zonal divergence time series at 10 and $50 \mathrm{~m}$. This transfer function was then applied to the Fourier coefficients of $u_{x}$ at $50 \mathrm{~m}$, calculated over the record gap interval in order to estimate the Fourier coefficients of $u_{x}$ at $10 \mathrm{~m}$, and a time series for $u_{x}$ at $10 \mathrm{~m}$ depth was then generated by inverse Fourier transformation.

Given the horizontal divergence, $w$ was then estimated by vertically integrating the continuity equation down from the surface using a rigid lid approximation (i.e., $w=0$ at $z=0$ ). Sea level time series at Saint Peter and Saint Paul Rocks $\left(0.92^{\circ} \mathrm{N}, 29.33^{\circ} \mathrm{W}\right.$; hereafter abbreviated as SPPR), presented by Cartwright et al. (1987), indicate that for periods greater than 2 days the maximum vertical rate of change of sea surface elevation is about $5 \times 10^{-5} \mathrm{~cm} \mathrm{~s}^{-1}$. This speed is two orders of magnitude smaller than the $w$ estimates obtained herein thereby justifying the use of the rigid lid approximation. Thus, at $10 \mathrm{~m}$ depth $w$ is computed as 


$$
\left.w\right|_{z=-10 \mathrm{~m}}=\int\left(u_{x}+v_{y}\right) d z
$$

where $u_{x}$ and $v_{y}$ are assumed constant over the upper $10 \mathrm{~m}$. At depths greater than $10 \mathrm{~m}, w$ is computed by trapezoidal integration between $-z_{1}$ and $-z_{2}$ with the integration constant at depth $-z_{2}$ set equal to the previously computed $w$ at depth $-z_{1}$, i.e.,

$$
\left.w\right|_{z=-z_{2}}=\int\left(u_{x}+v_{y}\right) d z+\left.w\right|_{z=-z_{1}} .
$$

A uniform depth increment of $10 \mathrm{~m}$ is used for the integration by linearly interpolating the horizontal divergence computed at 10,75 and $150 \mathrm{~m}$ depths, between these depths.

\section{Results}

\section{a. Winds}

Figure 1 shows time series of the surface wind stress components observed at SPPR for the period midFebruary-mid-November 1983 and January-March 1984 as reported by Garzoli and Katz (1984). For presentation here, these data have been low-pass filtered with a truncated Fourier transform to exclude oscillations at time scales shorter than 5 days. Supplemental wind data from a buoy at $0^{\circ}, 24^{\circ} \mathrm{W}$ are also available for the period September 1983-January 1984 to fill in the record gap at SPPR ( R. Payne, personal communication ). At the beginning of the SPPR record, weak southeasterly wind stress relaxed to near zero levels during the last week of March. By 10 April the zonal component, $\tau^{x}$, began to intensify reaching values of about -0.5 dyn $\mathrm{cm}^{-2}$ within two to three weeks, whereupon it then fluctuated about this relatively constant level through mid-November. Upon resumption of the record, the winds were very weak and remained so through March 1984 . The record at $0^{\circ}, 24^{\circ} \mathrm{W}$ further shows that the weakening in $\tau^{x}$ also occurred rapidly over a one month period beginning in mid-December 1983. The seasonal variability in the meridional wind stress component, $\tau^{y}$, mirrors that of $\tau^{x}$. Weak values are observed through mid-April, afterwhich $\tau^{y}$ intensified to a steady value of about $0.2 \mathrm{dyn} \mathrm{cm}^{-2}$. Upon relaxation in mid-December it then remained weak through May 1984. The 1983-1984 in situ wind observations differed from the climatological winds as given by Hellerman and Rosenstein (1983) in that the seasonal wind stress transitions from weak to strong easterlies and conversely occurred much more rapidly than has been suggested by climatology.

\section{b. Vertical component of velocity}

The results of the $w$ component calculations are summarized in Figs. 2 and 3. Figure 2 shows time series of $w$ at the instrument depths of $10 \mathrm{~m}, 75 \mathrm{~m}$ and 150 $\mathrm{m}$ low-pass filtered using a truncated Fourier transform to exclude oscillations at time scales shorter than 5 days (solid lines) and 30 days (dashed lines), respectively. Figure 3 shows 10-day low-pass filtered isotachs of $w$ as a function of time and depth (left hand plate) and vertical profiles of the record length means (righthand plate) where the squares are estimates using the original data and the crosses are estimates using an empirical orthogonal function (EOF) analysis as a spatial filter on the data. Also included in the righthand plate are the standard deviations, given in parentheses, of the estimates at $10 \mathrm{~m}, 75 \mathrm{~m}$ and $150 \mathrm{~m}$ depths.

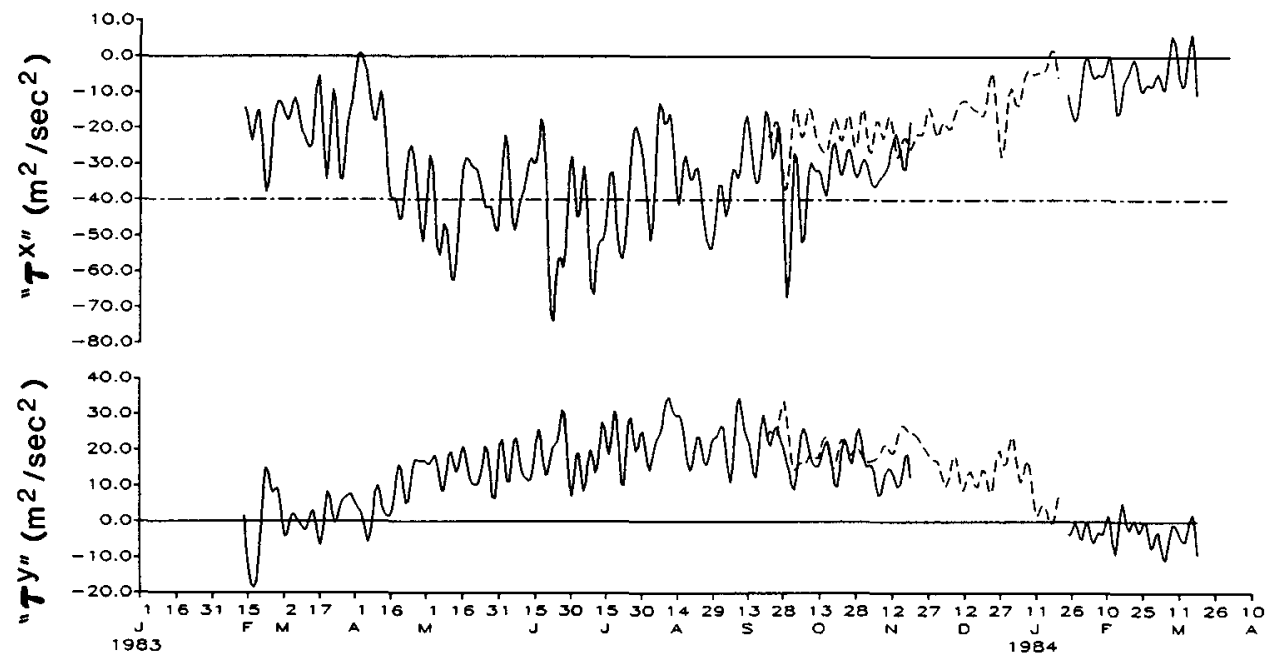

FIG. 1. Zonal (" $\tau^{x ")}$ and meridional (" $\tau^{y ")}$ surface wind stress component proportionals measured at SPPR (solid line) and at $0^{\circ} \mathrm{N}, 24^{\circ} \mathrm{W}$ (dashed line), low pass filtered to exclude fluctuations at time scales shorter than 5 days. Using the stress formulation of Garzoli and Katz (1984) the proportional value of -40 $\mathrm{m}^{2} \mathrm{~s}^{-2}$ is equivalent to a wind stress of about $-0.5 \mathrm{dyn} \mathrm{cm}^{-2}$ as denoted by the dot-dash line. 


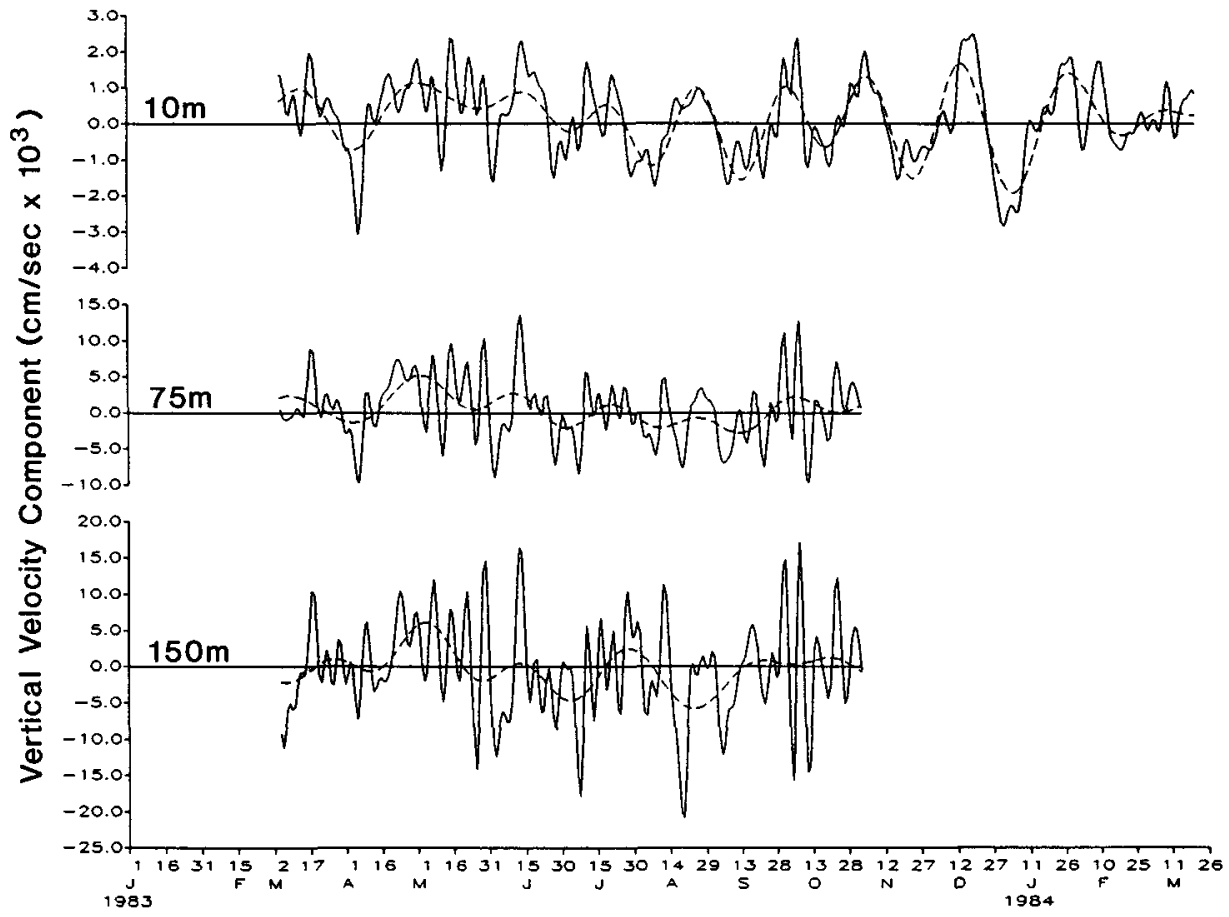

FIG. 2. Time series of $w$ estimated at depths of $10 \mathrm{~m}, 75 \mathrm{~m}$ and $150 \mathrm{~m}$, low-pass filtered to exclude fluctuations at time scales shorter than 5 days (solid line) and 30 days (dashed line).

Figure 2 reveals several distinctive features. Most striking is the high variability in $w$ with episodes of upwelling and downwelling occurring at all depths over a broad range of frequencies. The amplitudes of the high frequency oscillations (which generally are coherent over all depths) are large and tend to obscure the annual cycle. From this figure and Fig. 3 it is clear that the magnitude of the variability is tenfold that of the means. The $10 \mathrm{~m}$ depth provides the longest time series for describing the annual cycle. Beginning in late
March and coincident with the relaxation of the easterly wind stress component, intense downwelling is observed to last for about two weeks. Upwelling commences after the first week of April, coincident with the rapid intensification of the easterly wind stress component. Note that the period of relatively steady and intense upwelling lasts only for about one month. Then, from late May through June, sequential reversals in $w$ occur which are associated with waves of 25-day period, that are generated by surface current instability
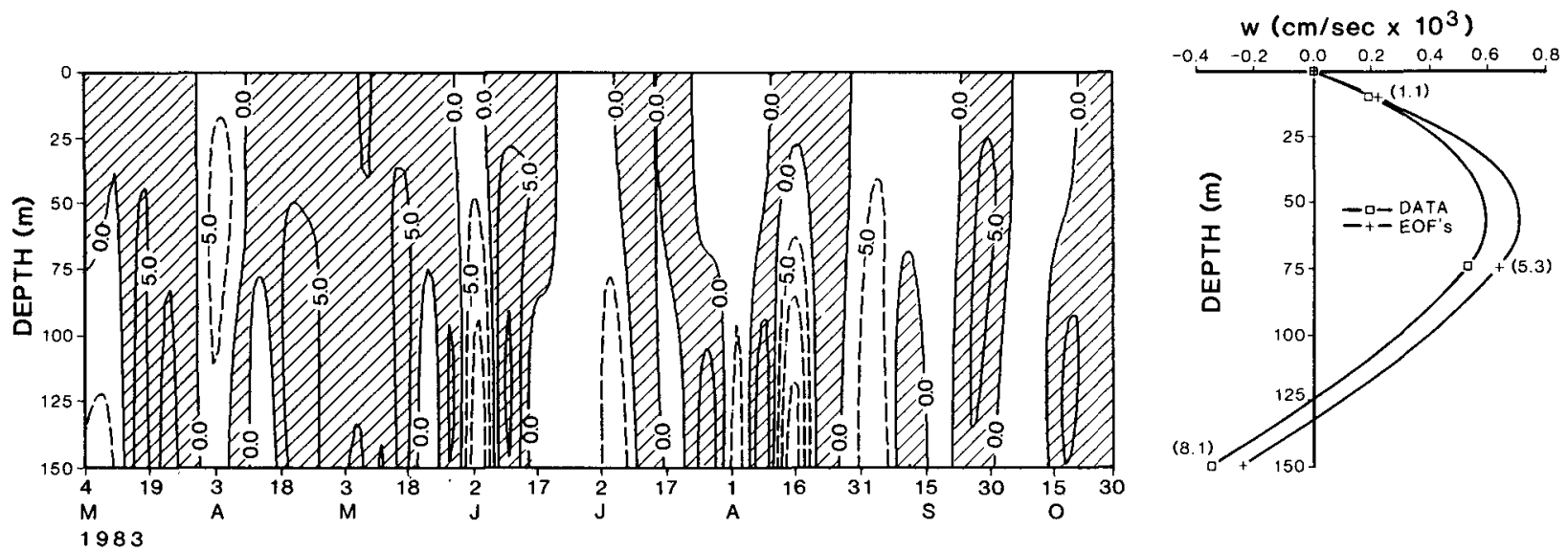

Fig. 3. Isotachs of $w$ as a function of time and depth, low-pass filtered to exclude fluctuations at time scales shorter than 10 days, and vertical profiles of record-length means and standard deviations (enclosed by parentheses) for $w$ computed from daily estimates using the original data and the EOF modes. 
(Philander et al. 1987; Weisberg and Weingartner 1988). Following the instability wave season the vertical motion from July through September, while highly variable, is on average downward despite the fact that the easterly wind stress component remains well developed. Some of this variability is clearly related to fluctuations in the easterly wind stress component as developed in section 4 . Coincident with the seasonal relaxation of the easterly wind stress component in mid-December, downwelling again occurs followed by upwelling from January to March, despite the fact that the easterly wind stress component is very weak. The summertime downwelling, occurring when the easterly wind stress component is at its seasonal maximum, is observed more clearly at the 75 and $150 \mathrm{~m}$ depths. Upon additional smoothing, Fig. 3 shows that the response in $w$ over the upper $150 \mathrm{~m}$ at this location during the season of strong Southeast Trade Winds consists of a transition from strong upwelling immediately following the intensification of the easterly wind stress component to weaker downwelling approximately one month later, and with this downwelling continuing through the summertime period of strong easterlies.

After averaging out the seasonal transition, the record-length mean $w$-profiles (computed either from the original data or the EOF fit to these data) suggest that upwelling occurs above the base of the thermocline at $130 \mathrm{~m}$ and downwelling occurs below it. Maximum upwelling at a rate of $0.6-0.7\left(\times 10^{-3}\right) \mathrm{cm} \mathrm{s}^{-1}$ (depending upon the calculation) occurs at $60 \mathrm{~m}$ depth, just above the mean depth of the Equatorial Undercurrent's (EUC) high speed core. The variability about these mean values is large as shown by the time series standard deviations, which range from $1.1 \times 10^{-3} \mathrm{~cm}$ $\mathrm{s}^{-1}$ at $10 \mathrm{~m}$ to $8.1 \times 10^{-3} \mathrm{~cm} \mathrm{~s}^{-1}$ at $150 \mathrm{~m}$. These variations are so large as to render the mean profile statistically insignificant. A corollary to this finding is that short term measurement programs can not yield results on equatorial ocean vertical velocity profiles that are representative of long-term means. A similar conclusion was arrived at by HF.

\section{c. Errors}

Three major sources of error may be identified: measurement error and the random and finite differencing errors due to sampling. Halpern and Freitag, using the divergence theorem, estimated the measurement error from the array geometry and the magnitude of the velocity sensor error [claimed from instrument intercomparison tests (Halpern 1987) to be $1.0 \mathrm{~cm}$ $\mathrm{s}^{-1}$ ] and concluded that the measurement error, which increases with depth by integration, can be as large as the estimated $w$. It should be noted, however, that measurement error, if random, is mitigated by averaging. By considering each horizontal velocity vector measurement to consist of a signal plus an uncorrelated Gaussian deviation, the measurement error for $w$ may be estimated directly from Eq. (1) by calculating the root-mean-squared deviation for each sample divided by the square root of the number of independent samples (four per hour) obtained. The descriptions of Figs. 2, 3 point out periods of upwelling and downwelling subsequent to the seasonal intensification of the easterly wind stress component. Since the averaging intervals are so long (approximately one month for the upwelling and three months for the downwelling), the measurement errors are found to be less than an order of magnitude smaller than the estimated values of $w$ for these periods. This is true even if we consider an unrealistically large random measurement error of $10 \mathrm{~cm} \mathrm{~s}^{-1}$.

Random sampling errors may be a more difficult problem for both specific periods of observation and record length means. In describing the results for the estimated $w$ several different events are attributed to variations in the surface wind stress or other ocean processes. While there is cause for making these assertions, as will be developed later, it is recognized that several independent realizations, over several years of record, for specific periods of observation such as the springtime upwelling period, would be required in order to construct meaningful confidence limits, determined from the random variations, during those periods. Also, the record-length mean values given in Fig. 3 are not statistically significant since the variances of the $w$ estimates are large relative to the integral time scales estimated to be about one month from their autocovariance functions.

Finite differencing to arrive at divergence estimates is also troublesome. Coherency alone is not sufficient to quantify these errors since coherence can be degraded by any bandwidth broadening process. For example, if $v$ responds antisymmetrically about the equator to $\tau^{x}$ forcing but symmetrically about the equator to $\tau^{y}$ forcing then the coherence between $v$ observed to the north and south of the equator will be degraded even if these variables at any point in time are represented by functions with smooth first derivatives. One would actually have to measure the structure of the velocity field over the scale of the array to ascertain the magnitude of the higher order derivatives or obtain estimates of divergence over a multiple of scales in order to place error bars on the finite difference calculation.

Filtering the dataset using EOFs was an attempt to reduce both random and finite differencing errors. The EOF-derived results were approximately the same as the data-derived results as shown in Fig. 4 where the two calculations are compared at $75 \mathrm{~m}$ depth. At 10 $\mathrm{m}$ depth the comparison is slightly better and at 150 $m$ it is slightly worse since all sources of error accumulate by vertical integration. Since there is a certain arbitrariness in deciding which modes to keep and which to exclude, we opted to use the data-derived results. What is encouraging is that the two different approaches gave such similar results. The array was small enough to resolve the most energetic fluctuations - the 

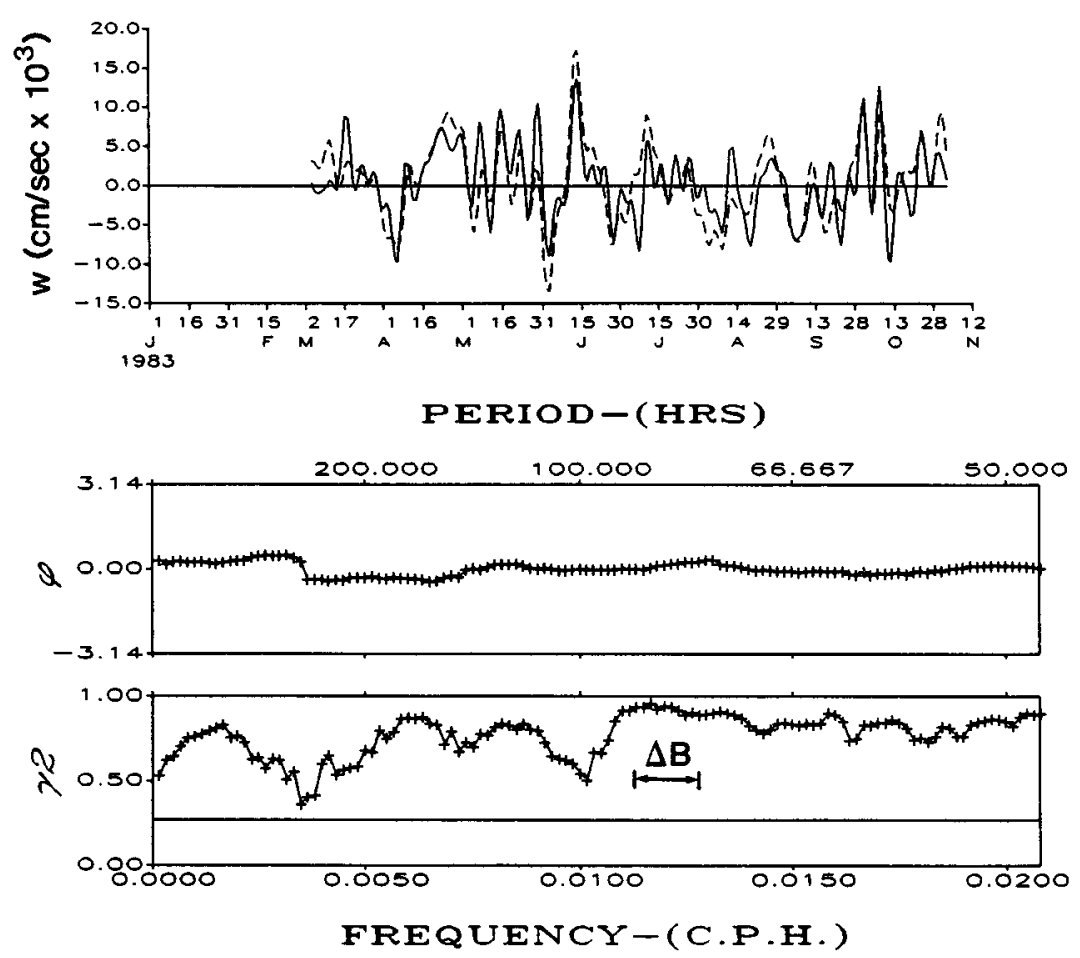

FIG. 4. (a) A comparison between $w$ time series estimated at $75 \mathrm{~m}$ depth using the original data (solid line) and the EOF modes (dashed line). (b) Coherence squared and phase between these two time series computed over the entire record: 4 March 1983-2 November 1983. The spectral estimates were computed over a bandwidth of $0.0014 \mathrm{cph}$ with approximately 17 degrees of freedom. The resulting $90 \%$ significance level is indicated by the horizontal line.

instability waves and the seasonal cycle. Apparently these were also the most divergent fluctuations.

There are two additional sources of error involved in the estimation of $u_{x}$ at $10 \mathrm{~m}$ depth during the period of the record gap. The first error results in a bias due to the lack of a mean value for $u_{x}$ over this gap. However, from the mean and standard deviation of $u_{x}$ at $10 \mathrm{~m}$ depth during the period May-September 1984 of $-0.7 \times 10^{-7} \mathrm{~s}^{-1}$ and $10 \times 10^{-7} \mathrm{~s}^{-1}$, respectively, the Student's t-test suggests that the mean is not significantly different at the $90 \%$ level from the zero value that was used. The second source of error arises from the linear mean square estimation procedure which introduces a random error of about $30 \%$ based on the estimated coherence between $u_{x}$ at 10 and $50 \mathrm{~m}$ depth.

The numerical error associated with an estimate of $w$ at the depth $z_{c}$ due to trapezoidal integration of $w_{z}$ is proportional to $h^{3} w_{z z z}\left(z_{c}\right)$, where $h$ is the depth increment of the integration and $w_{z z z}\left(z_{c}\right)$ is the third derivative with respect to depth of $w$ evaluated at $z_{c}$. If the profiles of $w$ are smoothly varying functions of depth as suggested by the observations, then this error will be unimportant. Improving the precision of the vertical velocity profile however requires additional independent estimates of horizontal divergence which in turn requires higher vertical resolution in the horizontal velocity measurements.

\section{Supporting evidence}

\section{a. Relationship between vertical velocity and temper-} ature

If vertical advection plays an important role in the upper-ocean heat balance on the equator as hypothesized, then the estimated $w$ should be consistent with the observed temperature variability. Figure 5 shows the coherence squared and phase between the temperature observed at the mid- to upper-thermocline depth of $75 \mathrm{~m}$ on the equator at $28^{\circ} \mathrm{W}$ and $w$ estimated there. These variables are coherent over the lowest resolvable frequency band and within the range of $0.005-0.016$ $\mathrm{cph}$, and the phase relationship of approximately $\pi / 2$ radians matches the expectation for vertical advection being important in the temperature variability. The incoherent low-frequency portion of the spectrum is also consistent with the estimation since this band coincides with the instability waves for which diabatic heating (Reynolds' flux convergence) is known to be important (Weisberg and Weingartner 1988).

Unlike the case at $75 \mathrm{~m}$ no significant coherence is found between the observed temperature and the estimated $w$ at $10 \mathrm{~m}$ depth. Nevertheless, there are distinct episodes when the estimated $w$ is found to be related to the temperature at this depth (SST) as is clearly discernable in Fig. 6 . The bottom two plates 
PERIOD - ( HRS )
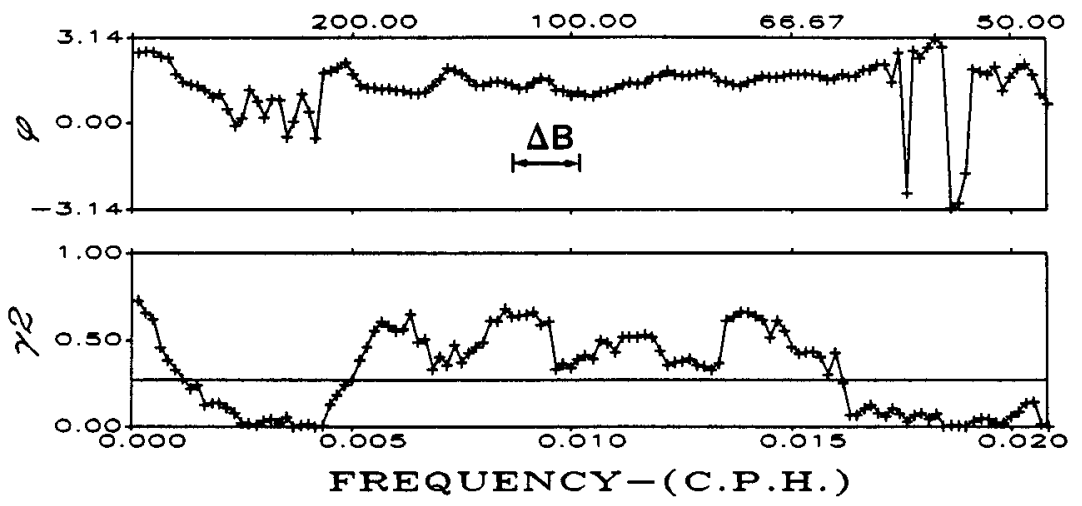

FIG. 5. Coherence squared and phase between temperature and $w$ at $75 \mathrm{~m}$ depth computed over the entire record: 4 March 1983-2 November 1983. The spectral estimates were computed over a bandwidth of $0.0014 \mathrm{cph}$ with approximately 17 degrees of freedom. The resulting $90 \%$ significance level is indicated by the horizontal line.

show the daily mean time series for $w$ and SST. Strong downwelling beginning in late March coincides with the basinwide collapse in easterly wind stress and an associated $1{ }^{\circ} \mathrm{C}$ increase in SST. Immediately following this downwelling period, and coincident with the seasonal intensification of easterly wind stress, is a con-

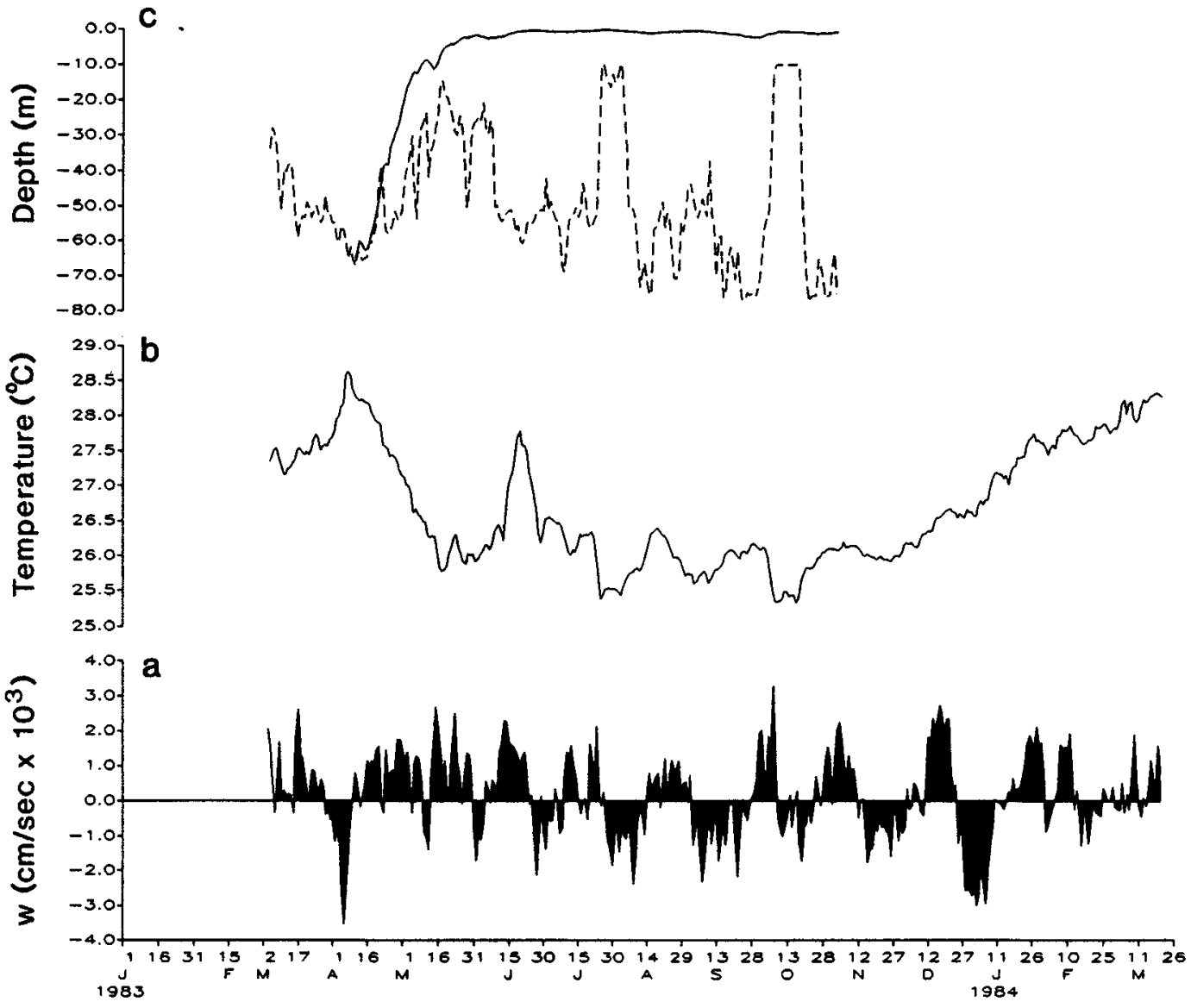

FIG. 6. (a) The daily mean $w$ time series estimated at $10 \mathrm{~m}$ depth. (b) The daily mean temperature at $10 \mathrm{~m}$ depth. (c) The observed depth of the $25.5^{\circ} \mathrm{C}$ isotherm (dashed line) compared with the depth of this isotherm estimated by integrating $w$ over time beginning with the onset of upwelling on 10 April (solid line). 
tinuous month-long upwelling event beginning the second week in April during which SST decreases by $3^{\circ} \mathrm{C}$. Mid-June shows a $2^{\circ} \mathrm{C}$ increase in SST but this time it is associated with upwelling! This particular observation of upwelling related to warming coincides with the instability wave season and it is consistent with the numerical model results of Philander et al. (1986), which shows that upwelling occurs under the warm troughs and downwelling occurs under the cold ridges of the instability waves. After the instability wave season, from mid-July through October, $w$ varies in quadrature with SST with upwelling (downwelling) leading to cooling (warming). These variations in $w$ and SST derive from similar variations in the easterly component of wind stress as mentioned earlier. Throughout the remainder of the record SST increases steadily as the mixed layer depth decreases (Weisberg et al. 1987). However, fluctuations in SST are not simply related to fluctuations in $w$, thus implying that other processes are controlling the evolution of SST during this time. Given the variations in mixed layer depth, the instability waves, and the role of other adiabatic and diabatic heating influences, the low coherence between the observed SST and the estimated $w$ at $10 \mathrm{~m}$ depth is due to the fact that neither the phase nor the gain between these two variables is constant throughout the record.

The relationship between SST and $w$ during the upwelling period of mid-April-mid-May is further explored in Fig. 6c, which compares the depth of the $25.5^{\circ} \mathrm{C}$ isotherm with the vertical displacement estimated by integrating $w$ over time beginning with the onset of upwelling on 10 April. The isotherm depth is determined by linear interpolation of temperature from the observations at $10 \mathrm{~m}, 50 \mathrm{~m}$ and $75 \mathrm{~m}$ depths. The displacement is based upon the depth-interpolated $w$ time series. From 10 April to mid-May the $25.5^{\circ} \mathrm{C}$ isotherm rises from a depth of $65 \mathrm{~m}$ to about $15 \mathrm{~m}$. Similiarly, the integral of $w$ from 10 April onward indicates that a parcel of fluid originating at $65 \mathrm{~m}$ depth rises to a depth of $10 \mathrm{~m}$ by mid-May. The onset of the instability wave season changes the temperature balance and hence the correspondence between vertical displacement and temperature. Beginning in early June, the $25.5^{\circ} \mathrm{C}$ isotherm deepens to about $60 \mathrm{~m}$ depth while the fluid parcel appears to remain within the upper 15 m. Weisberg and Weingartner (1988) showed that the warming of the surface layer at this time is related to the instability waves by the meridional convergence of Reynolds' heat flux.

During the instability wave season the observation of upwelling associated with warming further implies a positive correlation between $w$ and temperature. Figure 7 shows time series of the vertical Reynolds' heat flux proportional, $\left\langle w^{\prime} T^{\prime}\right\rangle$, at the observational depths between 10 and $150 \mathrm{~m}$. The primed terms are the deviations from 25-day running means of $w$ and temperature and the brackets denote the average over 25

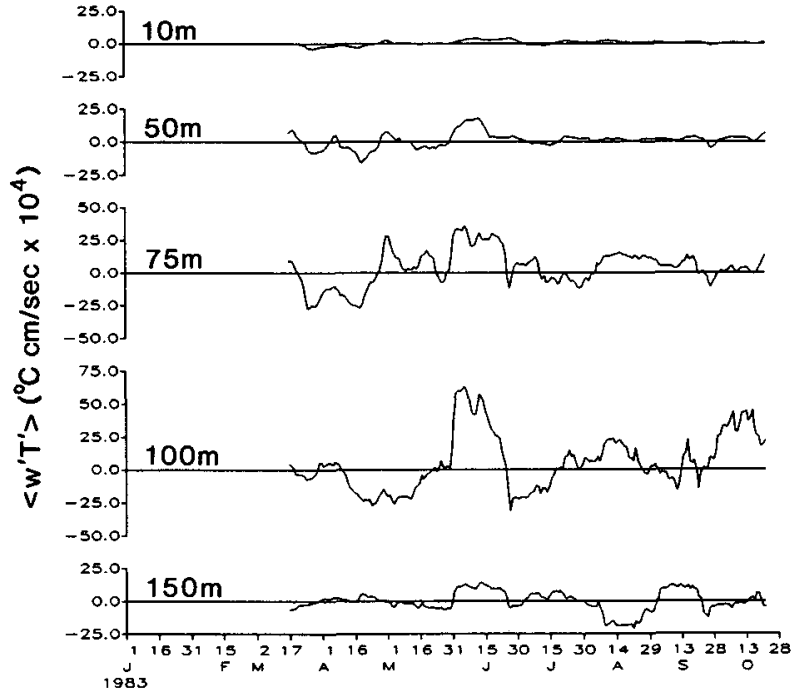

FIG. 7. Vertical Reynolds' heat flux proportional, $\left\langle w^{\prime} T^{\prime}\right\rangle$, time series estimated at depths of $10 \mathrm{~m}, 50 \mathrm{~m}, 75 \mathrm{~m}, 100 \mathrm{~m}$ and $150 \mathrm{~m}$.

days. At each depth $\left\langle w^{\prime} T^{\prime}\right\rangle$ is strongly modulated in time with maximum positive values observed in June when the instability waves are present. During the wave season this term increases monotonically from 10 to $100 \mathrm{~m}$ depths and then decreases at $150 \mathrm{~m}$ depth. The maximum values observed at $100 \mathrm{~m}$ implies a vertical convergence of heat flux within and above the thermocline and a divergence below it. This vertical distribution of $\left\langle w^{\prime} T^{\prime}\right\rangle$, obtained from observed $T^{\prime}$ and estimated $w^{\prime}$, is again in very good agreement with the numerical model results of Philander et al. (1986).

\section{b. Horizontal divergence}

The contributions to the horizontal divergence from the two coordinate directions are shown in Figs. 8 and 9. In each case the time series have been low-pass filtered to exclude oscillations at time scales shorter than 5 days. The zonal divergence, $u_{x}$, as given in Fig. 8 tends to be coherent over the upper $75 \mathrm{~m}$. Since the EUC slopes upward along the equator from the west to the east (along with the thermocline) the zonal flow below the depth of the EUC core should be convergent $\left(u_{x}<0\right)$. At $28^{\circ} \mathrm{W}$ the EUC core generally lies between 75 and $100 \mathrm{~m}$ depth, so the nearly uniform zonal convergence observed at $150 \mathrm{~m}$ depth with mean value of $-2.2 \times 10^{-7} \mathrm{~s}^{-1}$ is consistent with this expectation as is the variability and lack of preferred direction at 75 m depth. At $50 \mathrm{~m}$ depth $u_{x}$ shows a seasonal reversal with divergence occurring in spring when the EUC is nearest to the surface and convergence occurring in summer when the EUC is deepest. The former is consistent with the eastward shoaling EUC while the latter may have been due to the SEC, which was generally observed to be zonally convergent along the equator.

Consistent with the description of Defant (1936) and the theory of Stommel (1960) are the meridional di- 


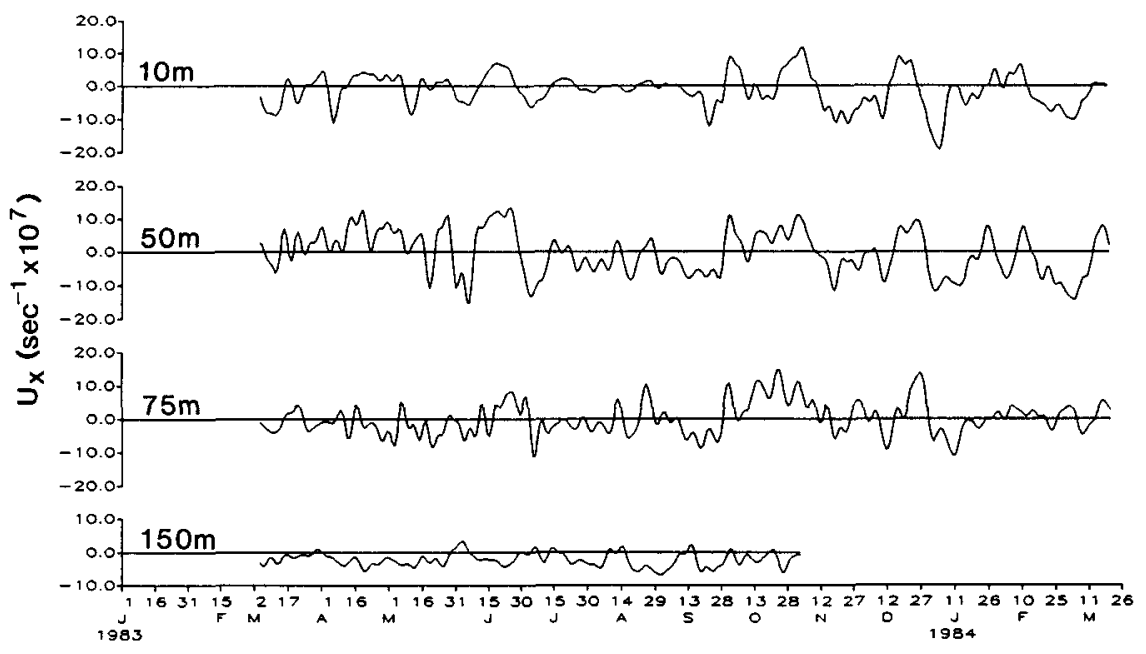

FIG. 8. The zonal divergence, $u_{x}$, time series estimated at depths of $10 \mathrm{~m}, 50 \mathrm{~m}, 75 \mathrm{~m}$ and $150 \mathrm{~m}$, low-pass filtered to exclude fluctuations at time scales shorter than 5 days.

vergences, $v_{y}$, as given in Fig. 9, which shows a mean divergence of $2.4 \times 10^{-7} \mathrm{~s}^{-1}$ at $10 \mathrm{~m}$ depth and a mean convergence of $-0.7 \times 10^{-7} \mathrm{~s}^{-1}$ at $75 \mathrm{~m}$ depth. Close inspection of the variability also reveals an interesting evolution. The springtime wind stress relaxation event of mid-March 1983 resulted in a large meridional convergence at $10 \mathrm{~m}$ depth along with a divergence at 75 $m$ depth. Beginning with the intensification of easterly wind stress in early April, $v_{y}$ is divergent at $10 \mathrm{~m}$ throughout this upwelling period but with no consistent relationship between the surface and the thermocline. A pattern does reemerge in mid-July with $v_{y}$ fluctuations at 10 and $75 \mathrm{~m}$ depths being approximately $\pi$ radians out of phase for time scales of about one month and in phase for time scales of about one week. This relationship is seen in the coherence squared and phase between $v_{y}$ at these two depths computed over the interval 15 July-2 November with a bandwidth of 0.0036 cph and approximately 18 degrees of freedom as shown in Fig. 10.

Apart from the clearer phase relationships suggested by the observations, there are several physical motivations for analyzing the second half of the record separately from the first. As discussed by Weisberg and Weingartner (1986) and Weisberg and Tang (1987), the adjustment process of the thermocline and the ZPG to rapidly varying easterly wind stress involves an overshooting of their intended equilibrium levels followed by a more gradual relaxation toward these levels. The first half of the record includes the period of rapidly varying wind stress, the instability waves, and the period when the ZPG is overshooting. During the second half

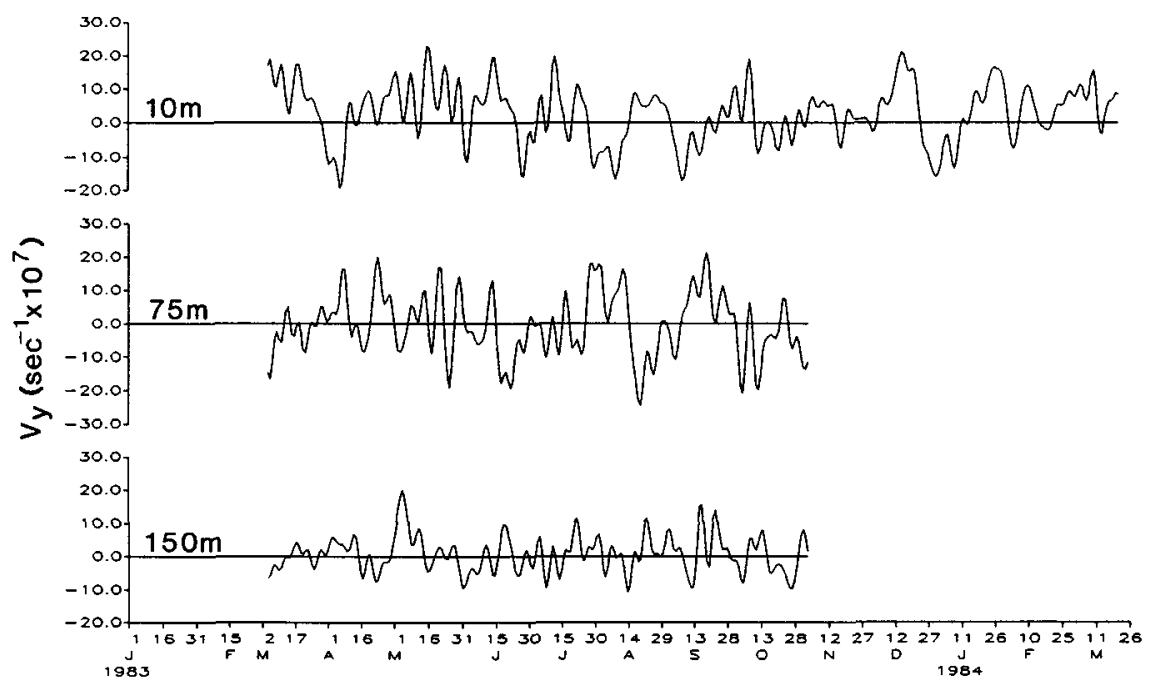

FIG. 9. The meridional divergence, $v_{y}$, time series estimated at depths of $10 \mathrm{~m}, 75 \mathrm{~m}$, and $150 \mathrm{~m}$, low-pass filtered to exclude fluctuations at time scales shorter than 5 days. 


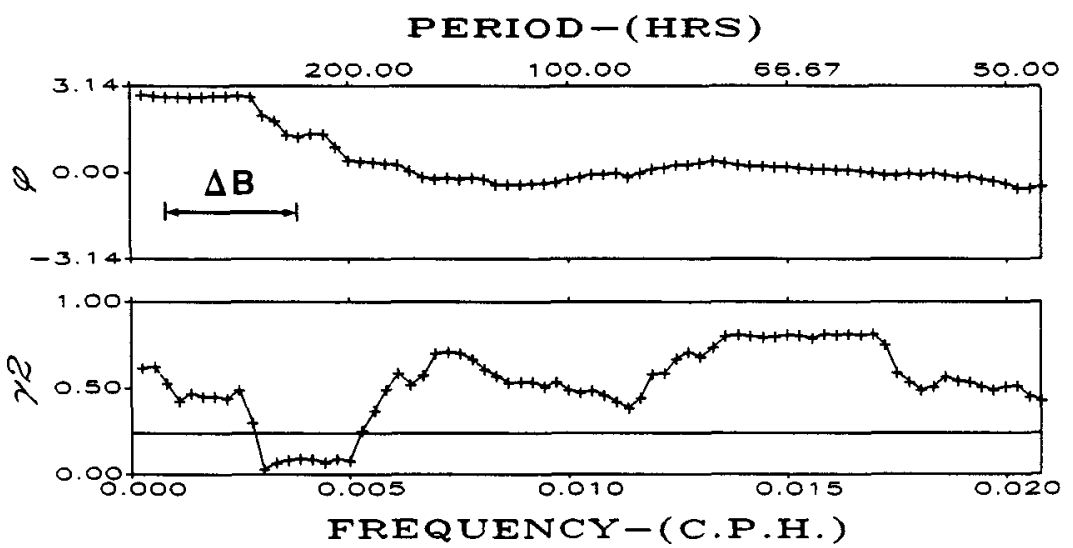

Fig. 10. Coherence squared and phase between $v_{y}$ estimated at $10 \mathrm{~m}$ and $75 \mathrm{~m}$ depths computed over the period 15 July 1983-2 November 1983. The spectral estimates were computed over a bandwidth of $0.0026 \mathrm{cph}$ with approximately 19 degrees of freedom. The resulting $90 \%$ significance level is indicated by the horizontal line.

of the record the instability waves abate and the ZPG gradually approaches equilibrium. Thus, it is during this second half of the record (when the thermocline is deep and the ZPG at $75 \mathrm{~m}$ depth is large) that the meridional circulation cell should be most clearly developed, and this is reflected in the low frequency outof-phase $v_{y}$ variability between the depths of 10 and $75 \mathrm{~m}$. The in-phase fluctuations of $v_{y}$ at higher frequencies may be related to inertio-gravity waves since their momentum balance is much less dependent upon the pressure gradient.

\section{c. The relationship between the wind stress, the velocity field, and the horizontal divergence terms, $u_{x}$ and $v_{y}$}

From February through November 1983, when simultaneous wind and water velocity measurements are available, $\tau^{x}$ at SPPR and $v$ at $10 \mathrm{~m}$ depth along $28^{\circ} \mathrm{W}$ tend to be incoherent. In contrast to this finding, $\tau^{x}$ shows some coherence with $v_{y}$ at low frequency, as given in Fig. 11, where the calculation is performed over a bandwidth of $0.0014 \mathrm{cph}$ for about 17 degrees of freedom. Where coherent, the phase is approximately $\pi$ radians implying that increasing easterly wind stress results in a surface divergence at the equator and conversely.

This finding of coherence between $\tau^{x}$ and $v_{y}$, in view of incoherence between $\tau^{x}$ and $v$ both to the north and south of the equator, may be the result of simultaneous excitation by the wind stress of $v$ component oscillations that are in-phase and out-of-phase about the equator. Southeast trade wind variability could cause this duality in phase since $\tau^{y}$ would lead to in-phase excitation while $\tau^{x}$ would lead to out-of-phase excitation. Upon differencing (summing) the $v$ component time series to the north and south of the equator the out-of-phase (in-phase) oscillations are preserved while the in-phase (out-of-phase) oscillations are removed. This is further explored by considering the relationship between $\tau^{y}$ and $v$. Figure 12 shows the coherence

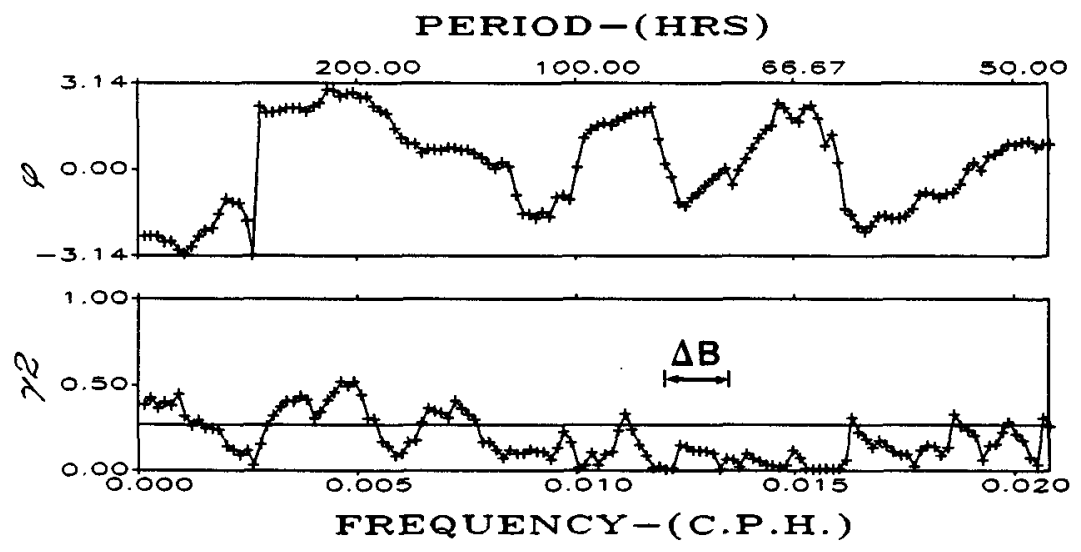

FIG. 11. Coherence squared and phase between $\tau^{x}$ and $v_{y}$ at $10 \mathrm{~m}$ depth computed over the period 4 March-19 November 1983. The spectral estimates were computed over a bandwidth of $0.0013 \mathrm{cph}$ with approximately 17 degrees of freedom. The resulting $90 \%$ significance level is indicated by the horizontal line. 


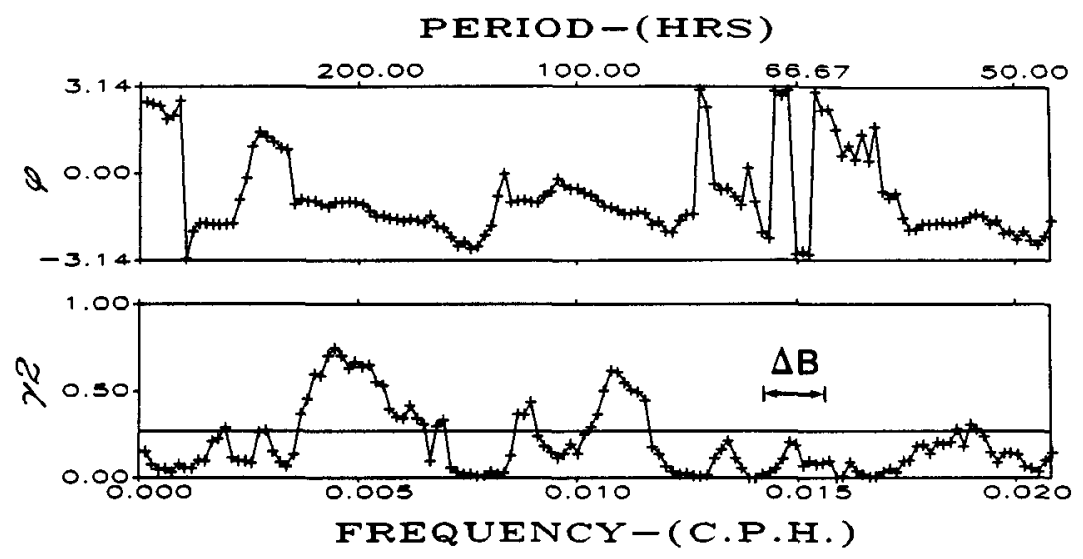

FIG. 12. Coherence squared and phase between $\tau^{y}$ and the sum of the $v$ components observed at $10 \mathrm{~m}$ depth along $28^{\circ} \mathrm{W}$ at $0.75^{\circ} \mathrm{N}$ and $0.75^{\circ} \mathrm{S}$ computed over the period $4 \mathrm{March}-19$ November 1983. The spectral estimates were computed over a bandwidth of $0.0013 \mathrm{cph}$ with approximately 17 degrees of freedom. The resulting $90 \%$ significance level is indicated by the horizontal line.

squared and phase between $\tau^{y}$ and the sum of the $v$ components observed at $10 \mathrm{~m}$ depth along $28^{\circ} \mathrm{W}$ at $0.75^{\circ} \mathrm{N}$ and $0.75^{\circ} \mathrm{S}$. Coherence is observed within frequency bands centered about 0.005 and $0.011 \mathrm{cph}$ where the fluctuations are approximately in quadrature. This phasing is consistent with resonant forcing of symmetric $v$ component oscillations by $\tau^{y}$.

Unlike $v$ or $v_{y}$, no coherence is found between $\tau^{x}$ or $\tau^{y}$ and the $u$ component at $10 \mathrm{~m}$ depth.

Combining the results for the individual velocity components, Fig. 13a,b shows the coherence squared and phase between $\tau^{x}$ and $w$ estimated at $10 \mathrm{~m}$ depth for the entire record and the second half of the record. These results are similar to those obtained between $\tau^{x}$ and $v_{y}$. The coherence derives primarily from the second half of the record as discussed previously, and the phase relationship is such that increasing easterly wind stress tends to increase the surface divergence (upwelling) and conversely.

In summary, several independent arguments have been presented to corroborate the vertical velocity component estimation. Qualitative corroboration is found in: 1) the relationship between $w$ and $T$ fluctuations at $75 \mathrm{~m}$ depth including the absence of coherence over the frequency band corresponding to the instability waves where we know that other processes are controlling, 2) the evolution of SST in relation to $w$ at $10 \mathrm{~m}$ depth during the time of the rapid seasonal wind stress transition; 3 ) the finding of upwelling under the warm troughs, downwelling under the cold ridges and the distribution of the vertical Reynolds' heat flux estimates during the instability wave season as shown in numerical model simulations, and 4) the development of the horizontal divergence and $w$ in relation to $\tau^{x}$. Quantitative corroboration is also given by the vertical displacement calculated from the estimated $w$ during the upwelling period immediately following the seasonal intensification of $\tau^{x}$.

\section{Discussion}

The principal result of this paper is that the annual cycle of $w$ on the equator in the central Atlantic differs in a fundamental way from that which may be inferred by casual observation of SST or calculated by climatological wind forced numerical models. As opposed to a lengthy upwelling season coincident with the period of strong easterlies, the results presented herein suggest that near-surface upwelling exists only for a brief period of time immediately following the seasonal intensification of easterlies. After this brief upwelling season $w$ reverses to downwelling despite the persistence of strong easterlies. This behavior can be explained by the rapidly varying nature of the wind stress observed in situ during 1983 (and subsequent years) as opposed to the slowly varying climatology.

Analytical studies have shown that the seasonal cycle in the equatorial upper-ocean velocity and temperature fields responds primarily to the zonal integral of $\tau^{x}$ along the equator, e.g., Cane and Sarachik (1977). Changes in the wind stress generates equatorial waves by accelerating currents and redistributing mass. These waves along with their boundary reflections then tend to bring the zonal pressure gradient into balance with the wind stress. The adjustment of the equatorial ocean to a switched-on easterly wind stress thus proceeds through three distinct periods (Philander and Pacanowski 1980): 1) an early stage, prior to the establishment of pressure gradients, when direct wind forcing predominates; 2) a middle stage when both the thermocline and the ZPG are responding rapidly to the passage of wave fronts; and 3 ) a final stage when the ocean has essentially reached equilibrium with the forcing.

Beginning with the rapid intensification in easterly wind stress on 10 April the observed seasonal variations in $w$ (as shown in Fig. 3 ) may be discussed relative to 

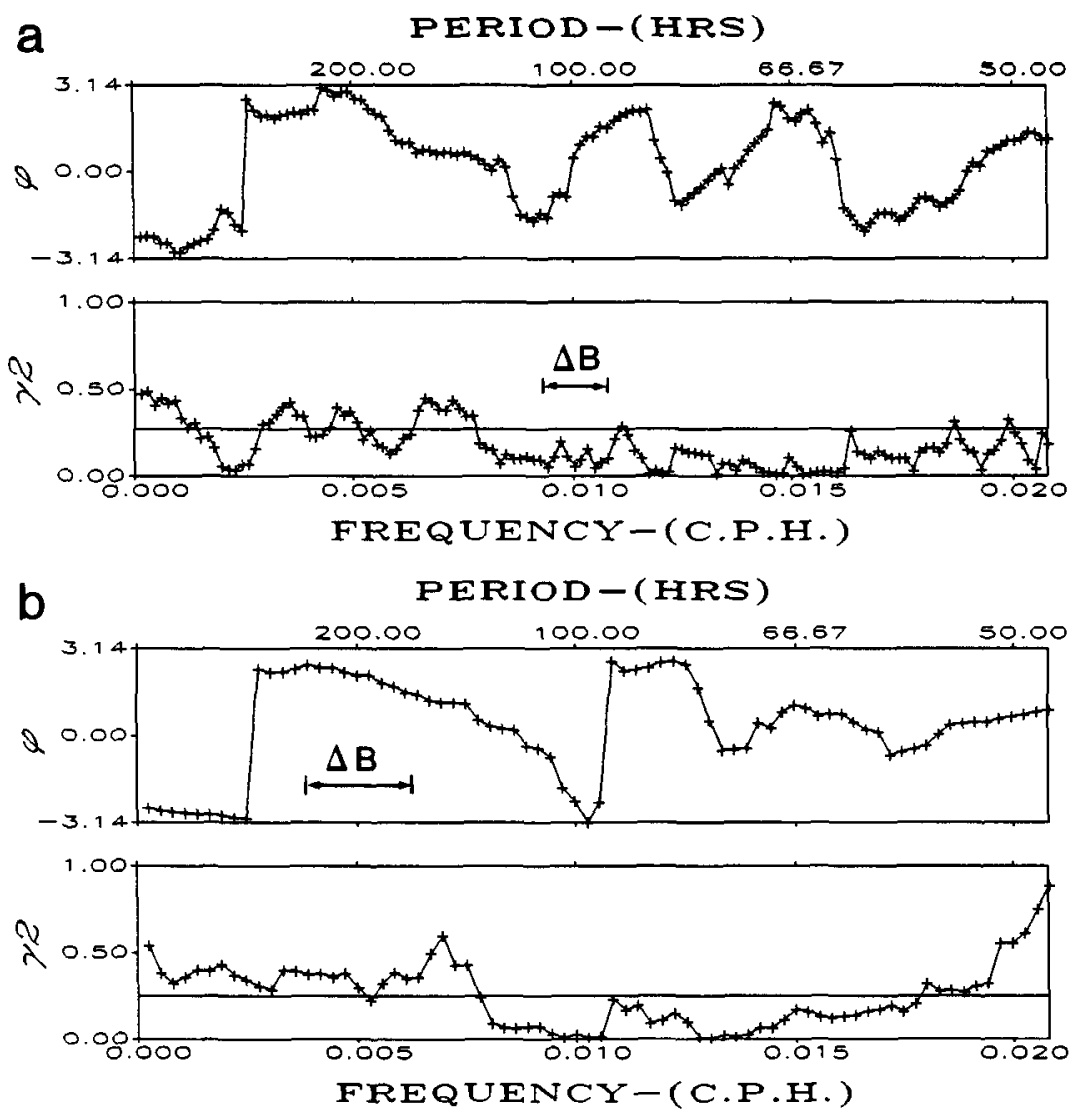

FIG. 13 (a) Coherence squared and phase between $\tau^{x}$ and $w$ estimated at $10 \mathrm{~m}$ depth computed over the period 4 March-19 November 1983. The spectral estimates were computed over a bandwidth of $0.0013 \mathrm{cph}$ with approximately 17 degrees of freedom. The resulting 90 percent significance level is indicated by the horizontal line. (b) As in (a) but for the period 15 July-19 November 1983. The spectral estimates were computed over a bandwidth of $0.0025 \mathrm{cph}$ with approximately 18 degrees of freedom. The resulting $90 \%$ significance level is indicated by the horizontal line.

these distinct periods. For the purposes of this discussion the influence of the instability waves on the seasonal evolution can be considered as a separate phenomenon whose effects are superposed upon the seasonal cycle.

Linear and nonlinear models (e.g., Cane 1980); Philander and Pacanowski 1980) forced by switched on easterlies show that the early stage is characterized by strong upwelling. The upwelling rate increases rapidly until either frictional effects limit its development or pressure gradient effects resulting from wave reflections off boundaries come into play. For realistic basin sizes and frictional parameter ranges, the frictional time scale of from days to weeks is shorter than the boundary reflection time scale from one to a few months. By parameterizing vertical friction with a linear damping term, $r u$, Cane (1980) showed that the vertical velocity into the surface layer approaches a steady value of

$$
w=-\beta \tau^{x} / r^{2} \rho
$$

at times larger than the frictional time scale of $r^{-1}$, where $\beta$ is the planetary vorticity gradient, $\rho$ is the den- sity of seawater, and $\tau^{x}$ is the eastward component of wind stress. From Fig. $6 \mathrm{c}$ an upwelling rate of 2.5 $\times 10^{-3} \mathrm{~cm} \mathrm{~s}^{-1}$, averaged between $60 \mathrm{~m}$ and $10 \mathrm{~m}$ depths, is established within a few days of the onset of easterly wind stress. From Eq. (4) the calculated frictional time scale of 1.7 days is consistent with this rapid establishment of this steady upwelling.

The middle stage of evolution starts when waves reflected from the ocean's boundaries begin to affect the adjustment of the thermocline and the ZPG. This adjustment includes a period of rapid downwelling during which the ZPG overshoots its intended equilibrium before gradually relaxing to it. For 1983, Weisberg and Weingartner (1986), Katz (1987), and Weisberg and Tang (1987) show that the ZPG overshooting response is largest in June and that equilibrium levels are attained by mid-September. During the period of overshoot the ZPG drives an equatorward geostrophic convergence which exceeds that required to balance the surface Ekman divergence. This results in a net meridional convergence of fluid everywhere within and above the thermocline. The observed mean meridional con- 
vergence at 10 and $75 \mathrm{~m}$ depth from July through midSeptember corroborates these physics.

In the final stage the thermocline and the ZPG are in equilibrium with the wind stress and Stommel's (1960) assumptions are more closely met. In this stage a meridional cell is set up with a net poleward flow at the surface compensated by a net equatorward flow at the depth of the thermocline. The out-of-phase relationship between $v_{y}$ observed at 10 and $75 \mathrm{~m}$ depths during the latter half of the record are consistent with this expectation.

The evolution of $w$ for slowly varying winds proceeds differently. In this case both the thermocline and the ZPG adjust on a time scale comparable to the winds so that the ZPG is always approximately in equilibrium with the wind stress. One way of discussing the differences in the seasonal variability of $w$ between rapidly varying and slowly varying wind stress is by letting $w$ $=w_{\theta}+\partial h / \partial t$, where $w_{\theta}$ is the vertical component of velocity due to the flow along isotherms, which tilt upwards toward the east, and $\partial h / \partial t$ is the local rate of change of isotherm depth. For slowly varying easterly winds $w_{\theta}>0$ and $|\partial h / \partial t|<w_{\theta}$ so that continuous upwelling would be expected. For rapidly varying easterly winds $w_{\theta}$ may be positive or negative since the isotherm slopes change (Weisberg and Weingartner 1986), $\partial h$ / $\partial t$ may also be positive or negative and $|\partial h / \partial t|$ may be $>\left|w_{\theta}\right|$. Consequently, both periods of upwelling and downwelling would be expected.

An example of these differences in $w$ between slowly varying and rapidly varying wind stress is given by comparing the data-derived results presented here and the climatological wind-forced numerical model simulation of Philander and Pacanowski (1986) as analyzed by Wacongne (1988). In the model, upwelling at $0^{\circ} \mathrm{N}, 25^{\circ} \mathrm{W}$ occurs above the thermocline throughout the year and it is greatest from September through November. In contrast, the observations show that $w$ varies seasonally with upwelling predominant from mid-April through May and downwelling predominant from mid-July through mid-September. These differences may be attributed to the differences in $\partial h / \partial t$ for slowly varying versus rapidly varying wind stress. Another factor contributing to the observation of a mean downwelling from July through mid-September is the zonal divergence term which is also in contrast with the model. At $50 \mathrm{~m}$ depth the data show a large zonal convergence throughout these months whereas the model shows a large zonal divergence.

In an effort to reconcile differences in the seasonal adjustment of the thermocline observed in the synoptic measurements versus climatology, Weisberg and Tang (1987) forced an analytical, reduced-gravity, equatorial long-wave model with a zonal wind stress representative of the variations observed along the equator in 1983 and 1984 . They found qualitative agreement between the model results and the data for most of the salient features observed over the annual cycle. These features were explained as a consequence of both directly forced and reflected waves which arise with each change in wind stress. The model simulated $w$ on the equator is shown as a function of longitude and time in Fig. 14. The model results show that the seasonal cycle in $w$ consists of: 1) a brief period of downwelling accompanying the basinwide relaxation of easterly wind stress in late March 1983, 2) an intense 1 to 1.5 month-long upwelling season accompanying the seasonal intensification of easterly wind stress beginning in early April 1983,3) a weak but predominantly downwelling season that persists despite strong easterly wind stress, and 4) a return to upwelling after the easterly wind stress relaxes in mid-December 1983. This pattern essentially replicates in 1984. The $w$ fluctuations in both the model and the data arise so as to bring the thermocline slope into equilibrium with the varying wind stress. Rapid variations in wind stress lead to rapid variations in $w$ and hence the short-lived but intensive upwelling season observed immediately after the easterly wind stress component switches on in boreal spring.

The observed transition from upwelling to downwelling during the season of strong easterly wind stress has important implications for depths below the thermocline. Upper-ocean convergence of fluid and downwelling implies that the ocean at depth must adjust to both heat and mass fluxes from above. During downwelling heat is transported to greater depth both by vertical advection and diffusion. This vertical heat flux may be balanced by a combination of horizontal diffusion and westward advection of cooler water from the east. Continuity further requires that this downwelled water be returned poleward which requires a westward pressure gradient force (Philander 1973). These implications are corroborated by the ZPG observations of Weisberg and Weingartner (1986). The isotherm slope contributions to the ZPG extends to greater depth after upwelling ceases and downwelling begins. Since the surface ZPG appears to be compensated for within the thermocline, Weisberg and Weingartner (1986) contend that the sloping isotherms below the thermocline result in a westward pressure gradient force there, which is consistent with the requirements for mass and heat balance in the presence of downwelling.

Although the mean downwelling observed from midJuly through mid-September may be surprising, other aspects of the results presented do corroborate previous observational and model studies. In particular, during the instability wave season the observations of $w$ agree with the numerical model findings of Philander et al. (1986), and the mean $w$ profile shown in Fig. $2 b$ corresponds to those obtained from observations in the equatorial Pacific by HF, Halpern et al. (1989), Bryden and Brady (1985), and from numerical simulations of the equatorial Atlantic by Philander and Pacanowski (1986). All of these mean profiles show that the depth of maximum upwelling is located above the core of the EUC and that downwelling occurs below the base of the thermocline. 


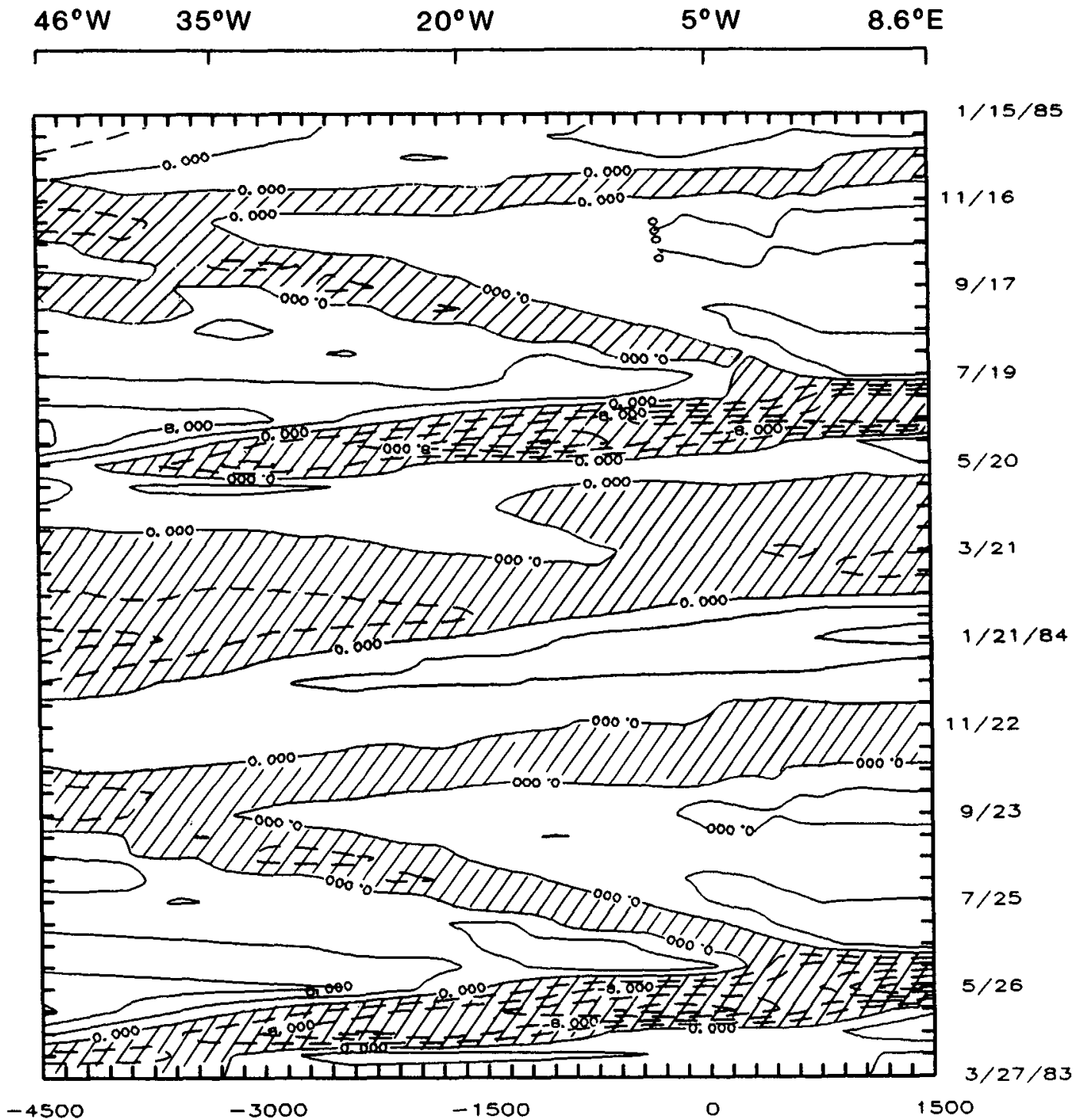

FIG. 14. The simulated $w$ from the model results of Weisberg and Tang (1987) as a function of longitude and time on the equator. Upwelling is denoted by stippling.

\section{Summary}

The annual cycle of the upper ocean's vertical velocity component $(w)$ was estimated on the equator at $28^{\circ} \mathrm{W}$ by vertically integrating the continuity equation between depths of $10 \mathrm{~m}$ and $150 \mathrm{~m}$ using horizontal velocity component data collected from a four-element array of surface-moored current meters deployed during the Seasonal Response of the Equatorial Atlantic (SEQUAL) Experiment. The annual cycle was found to consist of an intense but brief upwelling season beginning with the onset of strong easterly wind stress in boreal spring and lasting for approximately 1-1.5 months followed by weaker downwelling despite the persistence of strong easterly wind stress throughout summer. When averaged over the eight months of record the $w$ profile shows a maximum upwelling rate of
$0.6 \times 10^{-3} \mathrm{~cm} \mathrm{~s}^{-1}$ located just above the high speed core of the Equatorial Undercurrent and downwelling below the base of the thermocline. The variability in $w$ occurred over a broad range of time scales with standard deviations approaching ten-fold that of the means.

Since the potential sources of error may be large, several independent lines of evidence were marshalled in support of the results. Qualitative support followed from the observations that: 1) fluctuations in temperature and $w$ at $75 \mathrm{~m}$ depth were coherent and in quadrature over a broad frequency range exclusive of the instability wave band where diabatic processes are known to be controlling, 2) the variations in SST were related to $w$ estimated at $10 \mathrm{~m}$ depth during the rapid springtime changes in easterly wind stress, 3 ) during the instability wave season upwelling was found to be associated with increasing SST and the vertical Reyn- 
olds' heat flux was maximum and divergent in the thermocline as are known to occur, and 4) $w$ and $\tau^{x}$ were coherent and out-of-phase after the instability waves abated. Quantitative support followed from the agreement between the observed and computed isotherm displacement during the upwelling period immediately following the seasonal intensification in easterly wind stress.

The discussion focused upon the physical basis for the annual cycle of the estimated $w$, which was found to be in contrast with the annual cycle in $w$ suggested by climatological wind forced numerical model results. The differences, namely the short-lived upwelling season followed by downwelling versus continuous upwelling during times of strong easterly wind stress, were attributed to the ocean's response to the rapidly varying wind stress observed in situ versus the slowly varying climatology.

The results of this study bear upon several important topics for which equatorial upwelling is a critical component such as the mechanisms of northward heat flux in the Atlantic Ocean, the transport and exchange of transient tracers that have distinct distributions in the near surface equatorial waters, and biological productivity within the equatorial waveguide. Long time series of upper-ocean horizontal velocity, made with high vertical resolution over a multiplicity of horizontal scales, are required to resolve the annual mean and the intra-annual variability of the vertical motion and to assign confidence intervals to the estimation.

Acknowledgments. Support for this work was provided by the Oceanography Section of the National Science Foundation under Grant OCE-8211848 for the collection of the data and Grant OCE-8841927 for their analyses. The authors thank T. Y. Tang for many fruitful discussions and $\mathbf{J}$. Donovan for assistance with the data processing.

\section{REFERENCES}

Broecker, W., T.-H. Peng and M. Stuiver, 1978: An estimate of the upwelling rate in the equatorial Atlantic based on the distribution of bomb radiocarbon. J. Geophys. Res., 83, 6179-6186.

Bryden, H. L., and E. C. Brady, 1985: Diagnostic model of the threedimensional circulation in the upper equatorial Pacific Ocean. J. Phys. Oceanogr., 15, 1255-1273.

Bubnov, V. A., 1987: Vertical motion in the central equatorial Pacific. Oceanol. Acta, Proc. Int. Symp. on Equatorial Vertical Motion, 6, 27-32.

Cane, M., 1980: On the dynamics of equatorial currents, with application to the Indian Ocean. Deep-Sea Res., 27, 524-544.

- , and E. S. Sarachik, 1977: Forced baroclinic ocean motions, II: The linear equatorial bounded case. J. Mar. Res., 35, 395-432.

Cartwright, D. E., R. Spencer and J. M. Vassie, 1987: Pressure variations on the Atlantic equator. J. Geophys. Res., 92, 725-741.

Cromwell, T., 1953: Circulation in a meridional plane in the central equatorial Pacific. J. Mar. Res., 12, 196-213.

Defant, A., 1981: The Troposphere. W. J. Emery, Transl. Ed., Amerind.

Fine, R. A., W. H. Peterson, C. G. H. Rooth and H. G. Ostlund, 1983: Cross equatorial tracer transport in the upper waters of the Pacific Ocean. J. Geophys. Res., 88, 763-769.
Garzoli, S. L., and E. J. Katz, 1984: Winds at St. Peter and Paul rocks during the first SEQUAL year. Geophys. Res. Lett., 11, 715-718.

Halpern, D., 1987: Comparison of upper ocean VACM and VMCM observations in the equatorial Pacific. J. Atmos. Oceanic. Technol., 4, 84-93.

- , and P. H. Freitag, 1987: Vertical motion in the upper ocean of the equatorial eastern Pacific. Oceanol. Acta, Proc. Int. Symp. on equatorial vertical motion, SP, 19-26.

$\longrightarrow$, R. A. Knox, D. S. Luther and S. G. H. Philander, 1989: Estimates of equatorial upwelling between $140^{\circ} \mathrm{W}$ and $110^{\circ} \mathrm{W}$ during 1984. J. Geophys. Res., 94, 8018-8020.

Hansen, D. V., and C. A. Paul, 1984: Genesis and effects of long waves in the equatorial Pacific. J. Geophys. Res., 89, $10431-$ 10440 .

- and - 1987: Vertical motion in the eastern equatorial Pacific inferred from drifting buoys. Oceanol. Acta, Proc. Int. Symp. on equatorial vertical motion, 6, 27-32.

Hellerman, S., and M. Rosenstein, 1983: Normal monthly windstresses over the world ocean with error estimates. J. Phys. Oceanogr., 13, 1093-1104.

Katz, E. J., 1987: Seasonal response of the sea surface to the wind in the equatorial Atlantic. J. Geophys. Res., 92, 1885-1893.

Knauss, J. A., 1966: Further measurements and observations on the Cromwell Current. J. Mar Res., 24, 205-240.

Philander, S. G. H., 1973: The equatorial thermocline. Deep-Sea Res., 20, 69-86.

- and R. C. Pacanowski, 1980: The generation of equatorial currents. J. Geophys. Res., 85, 1123-1136.

, and - 1986a: The mass and heat budget in a model of the tropical Atlantic Ocean. J. Geophys. Res., 91, 14 212-14 220. , and - 1986b: A model of the seasonal cycle in the tropical Atlantic Ocean. J. Geophys. Res., 91, 14 192-14 206.

-, W. J. Hurlin and R. C. Pacanowski, 1986: Properties of long equatorial waves in models of the seasonal cycle in the tropical Atlantic and Pacific Oceans. J. Geophys. Res., 91, 14 20714211.

Quay, P. D., M. Stuiver and W. S. Broecker, 1983: Upwelling rates for the equatorial Pacific Ocean derived from the bomb ${ }^{14} \mathrm{C}$ distribution. J. Mar. Res., 41, 769-792.

Roemmich, D., 1983: The balance of geostrophic and Ekman transports in the tropical Atlantic Ocean. J. Phys. Oceanogr., 13, 1534-1539.

Sarmiento, J. L., 1986: On the north and tropical Atlantic heat balance. J. Geophys. Res., 91, $11677-11689$.

Stommel, H., 1960: Wind-drift near the equator. Deep-Sea Res., 6, 298-302.

Wacongne, S., 1988: Dynamics of the equatorial undercurrent and its termination. Ph.D. thesis, M.I.T./W.H.O.I. Joint Program.

Weisberg, R. H., and T. J. Weingartner, 1986: On the baroclinic response of the zonal pressure gradient in the equatorial Atlantic Ocean. J. Geophys. Res., 91, $11717-11725$.

- , and T.-Y. Tang, 1987: Further studies on the response of the equatorial thermocline in the Atlantic Ocean to the seasonally varying trade winds. J. Geophys. Res., 92, 3709-3727.

Atlantic Ocean. J. Phys. Oceanogr., 18, 1642-1657.

— J. H. Hickman, T.-Y. Tang and T. J. Weingartner, 1987: Velocity and temperature observations during the Seasonal Response of the Equatorial Atlantic Experiment at $0^{\circ}, 28^{\circ} \mathrm{W} . J$. Geophys. Res., 92, 5061-5075.

Wunsch, C., 1984a: An eclectic Atlantic Ocean circulation model. Part I: The meridional flux of heat. J. Phys. Oceanogr., 14, 1712-1733.

- 1984b: An estimate of the upwelling rate in the equatorial Atlantic based on the distribution of bomb radiocarbon and quasigeostrophic dynamics. J. Geophys. Res., 89, 7971-7978.

Wyrtki, K., 1981: An estimate of equatorial upwelling in the Pacific. J. Phys. Oceanogr., 11, 1205-1214.

, and G. Eldin, 1982: Equatorial upwelling events in the central Pacific. J. Phys. Oceanogr., 12, 984-988. 